\title{
Rendición de cuentas. A propósito de los sistemas de inteligencia en Argentina y Chile*
}

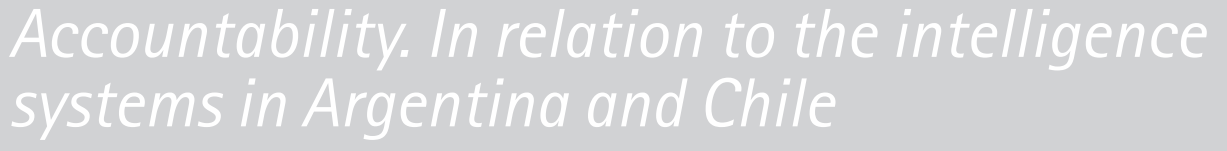

\section{Adrián S. Gimate-Welsh**}

\begin{abstract}
RESUMEN
El objetivo de este estudio es examinar la vigencia de la rendición de cuentas en el ámbito de los sistemas de inteligencia en Argentina y Chile. La hipótesis de trabajo consiste en dos supuestos apoyados en la conceptualización del Estado burocrático autoritario formulada por Guillermo O'Donnell. Supuesto 1: a mayor grado burocrático autoritario, rendición de cuentas endeble de los sistemas de inteligencia. Supuesto dos: a mayor calidad democrática, rendición de cuentas robusta, mayor control y supervisión de las instituciones de inteligencia. Ambas asunciones se ven como variables dependientes de la calidad institucional en el contexto de una democracia representativa robusta.

Para confirmar estas presunciones, se realiza un análisis del sistema de inteligencia en Argentina y Chile en el marco de las políticas de seguridad puestas en acción mediante reformas constitucionales e innovación institucional y de su encuadre en instrumentos de rendición de cuentas. El soporte metodológico es esencialmente cualitativo-interpretativo de textos sobre inteligencia en ambos Estados, sobre todo en el contexto del incremento del crimen y de la urgencia de acciones eficaces de prevención, detención y sentencia de los delincuentes.
\end{abstract}

\section{PALABRAS CLAVE}

Sistemas de inteligencia, sistemas de seguridad, rendición de cuentas, democracia y Estado.

\begin{abstract}
The objective of this study is to examine the validity of accountability in the field of intelligence systems in Argentina and Chile. The working hypothesis consists of two assumptions supported by the conceptualization of the Authoritarian Bureaucratic State formulated by Guillermo O'Donnell. Assumption One: To a greater authoritarian bureaucratic degree, weak accountability of the intelligence systems. Assumption Two: A greater democratic quality, robust accountability, greater control and supervision of intelligence institutions. Both assumptions are seen as dependent variables of institutional quality in the context of a robust representative democracy.

To confirm these presumptions, an analysis of the intelligence system in Argentina and Chile is carried out within the framework of the security policies put into action through constitutional reforms and institutional innovation and their framing in instruments of accountability. The methodological support is essentially qualitative-interpretative of texts on intelligence in both States, especially in the context of the increase in crime and the urgency of effective actions of prevention, detention and sentencing of lawbreakers.
\end{abstract}

\section{KEYWORDS}

Intelligence Systems, Security Systems, Accountability, democracy and State.

\footnotetext{
*Artículo recibido el 7 de septiembre de 2017 y aceptado para su publicación el 4 de diciembre de 2017

**Profesor Investigador Universidad Autónoma Metropolitan, México (nugo435512@gmail.com) ORCID: 0000-0003- 
SUMARIO

1. Introducción

2. Concepto de inteligencia

3. Análisis de los sistemas de inteligencia

4. Conclusiones generales

\section{INTRODUCCIÓN}

Desde el retorno a la democracia en la Argentina y en Chile, en 1983 y en 1990, respectivamente, las reformas constitucionales y la innovación institucional ha sido uno de los rasgos sobresalientes de los regímenes de gobierno de ambos países para atender la problemática de la inseguridad del periodo 1990-2015.

Entendido el Estado como el conjunto de instituciones, ${ }^{1}$ las leyes de seguridad y de inteligencia son una muestra en el caso argentino: la ley 25.554 de Defensa Nacional aprobada en 1998, la ley 24.059 de Seguridad Interior de 1991, y la ley 25.520 de Inteligencia en 2001. Estas tres leyes conforman el entramado normativo de seguridad argentina. En el caso de Chile, la ley 19.974 del 2004 crea el sistema de inteligencia del Estado chileno y la Agencia Nacional de Inteligencia (ANI), cuyos fines son proteger de la soberanía nacional, preservar el orden constitucional y producir análisis de inteligencia (artículo 4). Ésta depende de las facultades del ejecutivo. En la justificación del proyecto de ley, se alude a las deficiencias del sistema de inteligencia vigente en eficacia y respeto de los derechos humanos, así como de fiscalización de los servicios de inteligencia.

En el contexto transicional, estos países muestran avances democráticos desemejantes que se reflejan en la calidad de sus instituciones de acuerdo con la evaluación de los valores democráticos. Uno de estos valores es la transparencia y la rendición de cuentas. El indicador promedio de voz y rendición de cuentas para Argentina en el periodo 1996-2010 es de 58.83, mientras que el de Chile es de 79.98 percentiles. Corresponde observar que el ranking de Argentina en 1998 es de 57.46, inicio del periodo de crisis económica y financiera; en 2010, ocupa la posición 59.71; Chile incrementa su posición de 65.67 en 1998 a 82.70 percentiles en 2010 .

En el contexto delineado, y del origen normativo de los sistemas de investigación, los sistemas de inteligencia muestran huellas autoritarias, diferenciadas por el origen y momento de su normatividad, o por las facultades del poder político del ejecutivo al punto que la eficacia y efectividad de los objetivos de

\footnotetext{
${ }^{1}$ O'Donnell, Guilermo, El Estado burocrático autoritario, Buenos Aires, Belgrano, 1982
} 
las reformas institucionales se advierten resultados desemejantes, como se verá más abajo.

Merece destacarse que los sistemas policiales de investigación de Argentina y Chile exhiben diferencias en el ámbito conceptual. Mientras que Argentina, con las leyes 23.554 de Defensa Nacional de 1998 y 25.520 del 2001 del Sistema de Inteligencia, establece una hermenéutica diferencial entre seguridad nacional y seguridad interna, la ley 19.974 chilena contiene esta misma distinción en los artículos 21 y 22, y asigna a Carabineros y Policía de Investigación la función de investigación. Pero el decreto 20.460 del 9 de enero de 1979 establece que ambas instituciones policiales están tuteladas por el Ministerio de Defensa Nacional según el artículo 1 de dicho decreto, lo cual denota su carácter fuertemente militarizado y su atributo nacional.

En este marco, el objeto de estudio en este artículo es indagar cuáles son los mecanismos de control/rendición de cuentas de los sistemas de inteligencia de Argentina y Chile del periodo de la transición democrática. La hipótesis de trabajo consta de dos supuestos que remiten al tipo de instituciones del Estado. Presunción primera: a mayor grado burocrático autoritario y democracia representativa frágil, rendición de cuentas endeble de los sistemas de inteligencia. Presunción segunda: a mayor democratización, rendición de cuentas robusta, mayor control y supervisión de las instituciones de inteligencia. En este marco ideacional se traza las dimensiones de la rendición de cuentas que sirve de referencia para el estudio en el diagrama 1.

Diagrama 1. Sistema de inteligencia y rendición de cuentas.

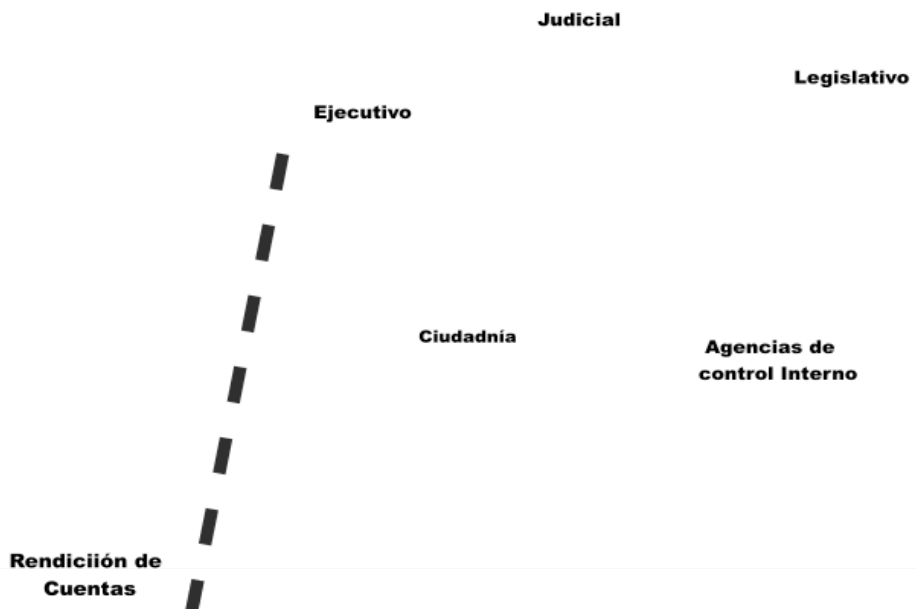


Enunciadas estas premisas, la rendición de cuentas de los sistemas de inteligencia es una variable de una democracia poliárquica, una democracia representativa con instituciones de supervisión, de control y con facultades para llamar a rendición de cuentas a los oficiales, elegidos o designados, que incumplen con su responsabilidad liberal y republicana. Estas dimensiones se instalan en la diada que propone 0'Donnell: liberal, que acontece en democracias que satisfacen el modelo poliárquico, casos de Argentina y Chile, en la que los agentes del Estado violan o permiten que agentes privados violen las libertades y garantías liberales, agentes que no rinden cuentas en los procesos electorales; y como complemento del círculo anterior, la dimensión republicana en la que los agentes, elegidos o nombrados, cometen acciones contrarias a sus responsabilidades, oficiales que priorizan el interés particular sobre el público y no son sancionados. ${ }^{2}$

En este escenario, el objetivo del ensayo es indagar si existen agencias del Estado que controlan, supervisan y sancionan agentes del Estado que transgreden las libertades y garantías constitucionales, los derechos humanos y priorizan el interés privado sobre el público, y si asumen su responsabilidad; y en qué medida las agencias cumplen con su responsabilidad de control y de rendición de cuentas de acuerdo con su normatividad interna.

Bosquejados el objeto de estudio y el propósito, la hipótesis y las variables de control y rendición de cuentas, resta enunciar el carácter cualitativo e interpretativo de la investigación. Primero, todo transcurso de lectura es un proceso de interpretación, acto de reescritura, ubicado histórica, espacial y actoralmente; $y$, en la medida que es un objeto histórico, se encuentra cruzado por objetos textuales de naturaleza diversa de carácter intertextual. Como tal, es un proceso interpretativo abierto.

Este estudio, al enfrentarse al texto concebido como documento abierto, no cerrado, asume un fuerte ingrediente interpretativo. Los textos, como fuentes de información, son de carácter primario en la medida en que proceden de documentos oficiales, textos primarios, o de textos que son producto de procesos de lectura y de interpretación de textos de naturaleza diversa. ${ }^{3}$

De ahí el carácter múltiple de las fuentes documentales que dan fortaleza a esta investigación -textos de expertos en el tema de seguridad de instituciones académicas y de instituciones públicas-, textos de naturaleza diversa -artículos especializados, capítulos de libros, ponencias, congresos en la materia,

\footnotetext{
2 O'Donnell, Guillermo, El Estado burocrático autoritario, Buenos Aires, Belgrano, 1982.

${ }^{3}$ Eco, UmBerto, Lector in fabula, Barcelona, Lumen, 1987.
} 
reportes periodísticos; textos de evaluaciones de funcionarios públicos, de organizaciones nacionales e internacionales; textos que contienen indicadores de medición del delito y del crimen-. Desde esta perspectiva, se instalan los procesos hermenéuticos de los textos que devienen fuente de esta investigación. De ahí su carácter interpretativo.

\section{ConcePto DE INTELIGENCIA}

La noción de inteligencia está ligada a la de información y seguridad. Con frecuencia, la información se reúne de manera clandestina. ${ }^{4}$ La información no siempre es confiable, los procedimientos para su obtención no siempre son los idóneos. Los funcionarios y los cuerpos policiales tampoco siguen los procedimientos de manera responsable, ${ }^{5}$ con la consecuente violación de los derechos humanos. Cualquiera de estas fallas implica ineficacia, ineficiencia y fracaso en el logro de los objetivos de las políticas securitarias.

Tomemos en consideración dos puntos. Primero, para que las acciones del personal de la institución confluyan en un mismo objetivo, este debe estar capacitado y actualizado permanentemente y la información protegida desde dentro y desde fuera. Segundo, concebida la institución como un todo orgánico, un sistema en el marco de una organización superior, el entramado institucional debe funcionar como un todo con miras a un mismo objetivo. Pero el todo no se limita al Estado; comprende la sociedad, sus estamentos y sus sectores. Luego entonces, la política securitaria, sus instituciones y el sistema de inteligencia deben mirarse en la perspectiva liberal y republicana.

El concepto de inteligencia se desagrega en tres dimensiones: 1) inteligencia militar con funciones específicas y propias de la Defensa Nacional, anclada en un marco legal definido constitucionalmente; 2) Inteligencia interna, cuyas acciones deben realizarse en el marco del Estado de derecho y respeto de las libertades civiles, los derechos humanos y las garantías constitucionales. En este ámbito, la institución debe someterse a la vigilancia y la supervisión; y 3) "la información en sí no constituye inteligencia [...] para que lo sea requiere que sea evaluada [...] proporciona técnicas que estructuran nuestros procesos

\footnotetext{
${ }^{4}$ Taylor, Stan \& Buchanan, Kayle, "Treason: 'tis Worse than Murder", Johnson, Loch K., The Oxford Handbook of National Security Intelligence, New York, Oxford University Press, 2010.

${ }^{5}$ Oficina de las naciones Unidas Contra la Droga y el Delito, Policía. Integridad y responsabilidad de la policía, Viena Nueva York, UNODC, 2010; véase también JoHnson, Lock, National Security Intelligence, Estados Unidos, Polity Press, 2012, pp. 2-21.
} 
deductivos naturales de pensamiento". ${ }^{6}$ El objetivo de la inteligencia criminal es proporcionar a las autoridades de seguridad los medios para actuar proactivamente en el combate al crimen organizado, una vez que se conoce su racionalidad operativa, sobre todo en circunstancias de políticas de prevención. La inteligencia criminal se divide en táctica u operativa y estratégica. ${ }^{7}$

La inteligencia táctica u operativa está orientada hacia un propósito policial determinado como el desmantelamiento de una organización criminal. La conforma un equipo de investigación provisto de hipótesis sobre aspectos específicos de las operaciones ilícitas del crimen organizado: redes criminales, organizaciones involucradas en actividades ilegales, sus capacidades y sus límites.

La inteligencia estratégica con fines de prevención delictiva, a corto, mediano y largo plazo, focaliza su atención en el análisis y evaluación de las tendencias delictivas del crimen organizado y sus ambientes de operación ilegal que amenazan la seguridad y el orden público. Su actividad de inteligencia puede conducir al diseño de nuevos programas y cambios en las leyes de seguridad.

Así, cualquiera que sea el modelo en que se suscriba, el denominador común en el campo semántico es la información evaluada que resulta de un proceso de análisis y de interpretación con el propósito de que sirva para la defensa de la seguridad nacional; o desde la perspectiva de la misión de la inteligencia: acopio de información y análisis, contrainteligencia y acción encubierta. ${ }^{8} \mathrm{La}$ noción de inteligencia ${ }^{9}$ se desagrega del modo siguiente en la figura número 1.

\footnotetext{
${ }^{6}$ United Nations Office on Drug and Crime, Criminal Intelligence. Manual for Analysts, New York, unodc, 2011.

7 Ugarte, José Manuel, "La inteligencia criminal en la seguridad pública Argentina", en Enrique Percio (coord.), Prejuicio, crimen y castigo, Buenos Aires, Sudamericana, 2010. Véase también United Nations Office on Drug and Crime, Criminal Intelligence. Manual for Analysts, New York, UNODC, 2011, p. 9.

${ }^{8}$ Johnson, Lock, National Security Intelligence, Estados Unidos, Polity Press, 2012, pp. 8-10; y Walsh, Patrick, Intelligence and Intelligence Analysis, New York, Routledge, 2011.

9 Jijón Calderón, Francisco, "El nuevo Ecuador y la Secretaría Nacional de Inteligencia", Fredy Rivera Vélez (coord.), Inteligencia estratégica y prospectiva, Ecuador, Flacso - AECID - OCED, 2011, define la inteligencia como: "información elaborada, información convertida en Inteligencia", p. 18.
} 
Figura 2. Inteligencia y su desagregación
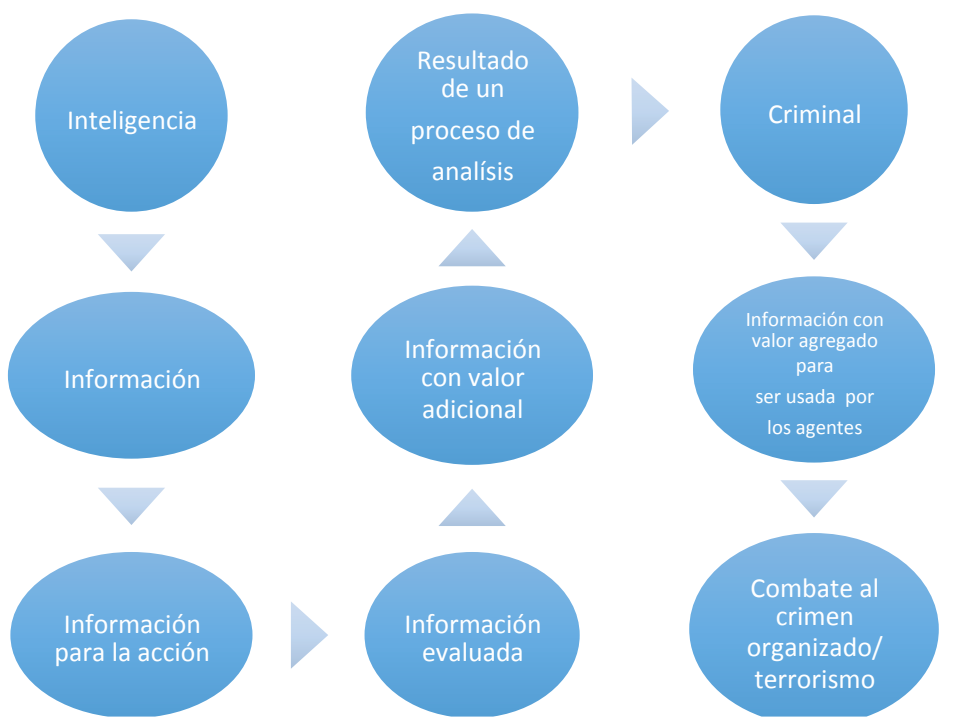

Fuente: Elaboración propia según formulaciones de Johnson, Lock, National Security Intelligence, Estados Unidos, Polity Press, 2012; Walsh, Patrick, Intelligence and Intelligence Analysis, New York, Routledge, 2011, y JiJón Calderón, Francisco, "El nuevo Ecuador y la Secretaría Nacional de Inteligencia”, Fredy Rivera Vélez (coord.), Inteligencia estratégica y prospectiva, Ecuador, Flacso - AECID - OCED, 2011.

En la obtención de la información, emerge uno de los puntos críticos que ha sido de debate político, parlamentario y de instituciones de defensa de los derechos humanos, es el tema de la vigilancia encubierta.

\subsection{Vigilancia encubierta}

El acopio de información mediante medidas encubiertas representa un frágil equilibrio entre la necesidad de obtener la información y la violación de las libertades y las garantías ciudadanas. Algunas leyes contienen en sus normatividades requerimientos previos que deben cumplirse antes de proceder a la obtención de información de fuentes como la intercepción de la comunicación privada (telefónica, internet, correo, redes). ${ }^{10}$ Este es el caso de la Ley 25.520 del 2001 de la Argentina hasta la aprobación de la reforma constitucional de 2015, con la Ley

\footnotetext{
10 Oficina de las naciones Unidas Contra la Droga y el Delito, Policía. Sistemas de información e inteligencia, Viena Nueva York, UNODC, 2010, p. 15.
} 
27.126. En su artículo 20, esta última establece penas de prisión de 3 a 10 años y la inhabilitación para aquellos funcionarios o personal de seguridad que intercepte información de las personas violando sus derechos a la privacidad.

En la ley 19.974 chilena, el artículo 24 estipula que en los casos de la obtención de información indispensable para la seguridad se puede intervenir la comunicación de "fuentes cerradas" (telefónicas, informáticas, redes y grabaciones) con autorización judicial por un periodo de noventa días, prorrogable por una sola ocasión. Sin embargo, la actividad encubierta en las actividades de inteligencia vulnera los derechos fundamentales y viola la ley, ${ }^{11}$ tengan éstas el éxito esperado o no. ${ }^{12}$

\section{ANÁlisis de lOS SISTEMAS de lNTELIGENCIA}

\subsection{Sistema de Inteligencia de Argentina. Rendición de cuentas}

Conforme con la Ley $25.520^{13}$ sobre el Sistema de Inteligencia Nacional, se propone realizar una revisión, discusión y análisis del sistema de inteligencia nacional argentino mediante un análisis comparado del Sistema de Inteligencia del Estado (Side) con la Agencia Federal de Inteligencia (AFI), que resulta de la reforma constitucional del 2015. Esta última incorpora una narrativa de los acontecimientos políticos y sociales que ponen de relieve los problemas de transparencia y rendición de cuentas del Side.

La narrativa de la Side, denominada previamente Coordinación de Informaciones de Estado (CIDE), ${ }^{14}$ creada durante el gobierno de Juan Domingo Perón en 1946 mediante el decreto 337/46, está plagada de acusaciones de corrupción y de ser instrumento político de los gobiernos en turno. ${ }^{15}$ Véanse los dos casos siguientes.

El rechazo y descrédito de la Secretaría de Inteligencia se hace evidente con dos acontecimientos suscitados en el gobierno de Fernando de la Rúa (19992001). El primero fue en el año 2000, cuando se dio a conocer que la Side había

\footnotetext{
${ }^{11}$ Reisman, Michael, "Covert Action", Yale Journal of International Law, vol. 20.

${ }^{12}$ ISenberg, David, "The Pitfalls of U.S. Covert Operations", Cato Institute Policy Analysis, núm. 118.

${ }^{13}$ Ley 25.520, "Ley de Inteligencia Nacional", Ministerio de Justicia y Derechos Humanos, Presidencia de la Nación, Argentina, 3 de diciembre de 2001. [Consulta: 20 de diciembre, 2016]. Disponible en: http://servicios.infoleg.gob.ar/ infoleglnternet/anexos/70000-74999/70496/texact.htm

${ }^{14}$ Kabat, Carina, "El peronismo, los orígenes de la Side, y de la maldita policia", Razón y revolución, segunda época, núm. 29, pp. 114-129.

${ }^{15}$ LA Nación, "Pasado, presente y futuro de la Side", La Nación. [Consulta: 11 de abril, 2017]. Disponible en: http:// www.lanacion.com.ar/841630-pasado-presente-y-futuro-de-la-side
} 
realizado pagos millonarios a senadores con el objeto de que votaran a favor de la ley laboral, iniciativa de gran importancia para el Ejecutivo, según declaraciones del exsecretario parlamentario, Mario Pontacuarto. Segundo, declaraciones de Alejandro Salomón, subsecretario de Seguridad en la Side en 2001.

El movimiento populista confunde permanentemente Estado y Gobierno. Al considerar que ellos (Gobierno) son el Estado, legitiman la utilización de los instrumentos de inteligencia con fines políticos partidistas. Por el mismo motivo por el cual en Argentina no existen Políticas de Estado, el peronismo no podrá tener una inteligencia del Estado, y la misma siempre será de gobierno. ${ }^{16}$

De acuerdo con Salomón, el control que ejerce la justicia siempre se media por la justicia federal, que depende de los aparatos de inteligencia para cualquier investigación. Por ello, es imperioso separar el vínculo de la justicia de los aparatos de inteligencia. Luego entonces, el análisis sobre la inteligencia en Argentina es tajante: no funciona la inteligencia militar, tampoco la inteligencia estratégica nacional, ni la inteligencia criminal. Desde su perspectiva, en el gobierno de Menem, la inteligencia estratégica dejó a un lado sus funciones y se convirtió en un instrumento de cooptación y corrupción de jueces, fiscales y periodistas, fenómeno conocido como "La cadena de la felicidad".

Esta sucinta reseña de la Side y su transformación en AFI en 2015 conduce al análisis del sistema de inteligencia de Argentina en el periodo de gobierno de Menem al de Cristina Fernández de Kirchner.

Con motivo de los atentados terroristas a la embajada de Israel (17 de marzo de 1992) y a la Asociación Mutualista Israelí-Argentina (AMIA, 18 de julio de 1994), durante el gobierno de Carlos Saúl Menem, la muerte del fiscal Alberto Nisman y el involucramiento, entre otras personalidades, del canciller argentino Héctor Timerman, el gobierno promovió acciones para llevar a cabo una reforma al sistema de inteligencia en 1994. La iniciativa quedó congelada en el congreso.

Las conclusiones a las que llega la Comisión Legislativa Bicameral muestran al menos dos caras de la problemática: fallas estructurales del entramado institucional de la seguridad pública; y la secrecía y el encubrimiento de los

\footnotetext{
${ }^{16}$ Salomón, Alejandro, "Pasado y presente de la Side. El repaso por lo que es hoy la Secretaría de Inteligencia", 26 de enero, 2015. [Consulta: 11 de abril, 2017]. Disponible en: http://www.mdzol.com/opinion/584497-pasado-y-presente-de-la-side/
} 
verdaderos ejecutores de los actos de terrorismo en el asunto de la embajada israelí y la AMIA.

En 2003, siendo presidente Néstor Kirchner (2003-2007), algunas organizaciones que proclamaban justicia denunciaron ante la Comisión Interamericana de Derechos Humanos (СіDH) al Estado argentino. Tiempo después, Kirchner tuvo que aceptar su responsabilidad, encubrimiento y denegación de justicia a los afectados:

Apruébese el Acta de fecha 4 de marzo de 2005 firmada en la Audiencia celebrada en el marco del 122 periodo ordinario de sesiones de la Comisión Interamericana de Derechos Humanos, en la petición №12.204 [...] en la que se reconoce responsabilidad del Estado nacional en relación con el atentado perpetrado el 18 de julio de 1994 contra la sede de la Asociación Mutual Israelita (AMIA), por incumplimiento de la función de prevención [...] y encubrimiento grave y deliberado de la función de investigación adecuada del ilícito, lo que produjo una clara denegatoria en justicia. ${ }^{17}$

El atentado de 1994, el peor en la historia argentina, cobró 85 víctimas y más de 300 heridos. Aún no resuelto después de 23 años, involucra, de algún modo y de acuerdo a la fiscalía especializada para la AMIA, a la expresidenta Cristina Fernández ${ }^{18}$ por el posible encubrimiento de supuestos autores iraníes del atentado en contra de la Mutual argentina-israelí. Una breve cronología indica que el fiscal Nisman, especializado en la indagatoria, denunció en el Juzgado Federal de Ariel Lijo, el 14 de enero de 2015, a la entonces presidenta Kirchner, al canciller Timerman, a personal de la ex-sIDE y a otros funcionarios de "confabulación criminal" por negociar un plan de impunidad y encubrir a prófugos iraníes acusados de la explosión a la mutual judía. ${ }^{19}$ Sus pruebas se respaldaron en audiciones de conversaciones telefónicas entre agentes de la SIDE y de informes iraníes. ${ }^{20}$ El 19 de enero de ese mismo año, el fiscal Nisman

\footnotetext{
${ }^{17}$ Decreto 812/2005, Boletín Oficial, núm. 30694, Ministerio de Justicia y Derechos Humanos, República Argentina, 12 de julio, 2005. [Consulta: 23 de junio, 2017]. Disponible en: http://servicios.infoleg.gob.ar/infoleglnternet/anexos/105000-109999/107751/norma.htm

${ }^{18}$ La Nación, "Atentado a la AMIA", La Nación. [Consulta: 22 de febrero, 2017]. Disponible en: http://www.lanacion. com.ar/atentado-a-la-amia-t48671

${ }^{19}$ Urgente 24, "Pacto de Irán: Denuncia y pedido de indagatoria a Cristina". [Consulta: 5 de mayo, 2017]. Disponible en: http://www.urgente24.com/235435-pacto-con-iran-denuncia-y-pedido-de-indagatoria-a-cristina

${ }^{20}$ En diciembre de 2015 fue del dominio público el conocimiento de audios entre el canciller Héctor Timerman y al dirigente de la AMIA, Guillermo Berger, en donde el canciller presiona al dirigente judio para que acepte las negociaciones con Irán sin cuestionar el Memorándum de Entendimiento; así como a Timerman reconocer que fue Irán la responsable del atentado a la AmiA.
} 
debía presentar ante el Congreso Nacional las pruebas, hecho que no sucedió, puesto que ese mismo día se encontró muerto. Para el 27 de enero, Fernández de Kirchner anunció por cadena nacional la reforma del sistema de inteligencia del Estado en un largo discurso que justificó el Memorándum de Entendimiento entre Argentina e Irán como medida de solución y justicia de los atentados. También hizo alusión a la exigencia de la aclaración de la muerte de Nisman, a la falsedad de las pruebas que se han presentado en más de 20 años y, de forma particular, a la creación de la AFI como una respuesta al problema del sistema de inteligencia nacional, deuda pendiente con la democracia desde 1983. ${ }^{21}$

¿Qué relación hay entre el caso AmIA y la ex-Side? Según información de la Unidad Fiscal de Investigación (UfI), se advirtió que la exsecretaría de Inteligencia produjo información que podía haber sido útil para la causa, antes y después del ataque, pero no la remitió hasta que fue descubierta en 2015.22

Lo que muestra esta narrativa del caso AmIA es la falta de control -interno y externo-, y supervisión de las acciones de los organismos de inteligencia. En esencia, la ausencia de la rendición de cuentas vertical y horizontal. La Secretaría de Inteligencia depende de la Presidencia de la Nación. De ahí el argumento de que el sistema de inteligencia es un instrumento político del ejecutivo federal.

La manifiesta falta de colaboración por parte de los distintos organismos de seguridad e inteligencia federales y provinciales que debieron coadyuvar al desarrollo de la investigación judicial debe entenderse desde una doble perspectiva que comprenda, tanto las fallas estructurales de los mismos, como la evidente decisión de obstruir el esclarecimiento de los hechos, y de encubrir a grupos sospechosos de haber participado en el atentado y vinculados al Estado. ${ }^{23}$

La exigua transparencia y rendición de cuentas del sistema de inteligencia argentino es semejante a la que se ha señalado para el caso de las instituciones policiales: disfrutan de una cómoda y beneficiosa autonomía que se manifiesta en la discrecionalidad del uso de los recursos y en la secrecía de sus acciones; sólo responden al poder político nacional y provincial.

\footnotetext{
${ }^{21}$ Presidencia de la Nación, "Reforma del Sistema de Inteligencia del Estado", Argentina, 27 de febrero, 2015. [Consulta: 13 de enero, 2016]. Disponible en: http://www.casarosada.gob.ar/informacion/discursos/28321-reforma-del-sistema-de-inteligencia-del-estado-anuncio-de-la-presidenta-de-la-nacion-por-cadena-nacional

22 Télam, "Amia: Ios fiscales alertan que la ex-Side no envió información a la justicia", 16 de octubre, 2016. [Consulta: 2 de enero, 2016]. Disponible en: http://www.telam.com.ar/notas/201610/167167-causa-amia-fiscales-ex-side-informacion.html

${ }^{23}$ Serrano Torres, Jorge, "¿Acabará la manipulación e ineficacia? Kirchner y el sistema de inteligencia argentino", Voltaire Net, 26 de septiembre, 2004. [Consulta: 2 de enero, 2016]. Disponible en: http://www.voltairenet.org/article121590.html
} 
La Asociación por los Derechos Civiles (ADC) dice: "Los organismos de inteligencia gozan de una inaceptable autonomía y continúan siendo un actor de peso en el sistema político gracias a leyes ineficientes y a un amplio arco político dispuesto a mirar hacia otro lado". ${ }^{24}$ El Centro de Estudios Legales y Sociales esgrime a su vez: "En un contexto en el que quedó expuesto el intolerable nivel de autonomía del aparato de inteligencia nacional y sus relaciones espurias con el sistema político y judicial, la nueva regulación debería ser parte de una reforma orientada a profesionalizar la actividad y subordinarla al gobierno democrático", ${ }^{25}$ entendido este en términos poliárquicos en un Estado liberal y republicano.

No hay controles efectivos de los servicios de inteligencia. Las acciones de la inteligencia nacional violan el derecho a la privacidad, a la libertad de asociación y la libertad de expresión. Las libertades básicas de la ciudadanía democrática son objeto de vigilancia por parte del Estado. ${ }^{26}$ Los esfuerzos de democratizar las fuerzas armadas, los mecanismos de seguridad y los sistemas de inteligencia de parte del poder legislativo han sido insuficientes. ${ }^{27}$ En suma, los sistemas de inteligencia militares y civiles vulneran los valores democráticos, uno de ellos, la rendición cuentas horizontal y vertical. Después de 22 años de los acontecimientos de terroristas a la Mutual Argentina-Israelí, los culpables no han sido llevados a juicio.

En este escenario, debe reconocerse que los esfuerzos de la sociedad civil por democratizar las fuerzas armadas y de seguridad interna a cargo de la Gendarmería Nacional han sido múltiples. ${ }^{28}$ Una muestra de ello lo constituye el Seminario Control Democrático de los Organismos de Seguridad en la República Argentina de 1997.

${ }^{24}$ Asociación por los Derechos Civiles, El (des)control democrático de los organismos de inteligencia en Argentina, Argentina, ACD, 2015, p. 1. [Consulta: 8 de julio, 2017]. Disponible en: http://www.adc.org.ar/wp-content/ uploads/2015/01/2015-01-23-Informe-Final-Inteligencia.pdf

${ }^{25}$ Chillier, Gaston, "Prólogo", Centro de Estudios Legales y Sociales, Derechos humanos en Argentina. Informe 2015, Buenos Aires, Siglo XXI - cels, 2015, p. 26.

${ }^{26}$ Asociación por los Derechos Civiles, El (des)control democrático de los organismos de inteligencia en Argentina, Argentina, ADC, 2015. [Consulta: 8 de julio, 2017]. Disponible en: http://www.adc.org.ar/wp-content/ uploads/2015/01/2015-01-23-Informe-Final-Inteligencia.pdf

${ }^{27}$ Cawthra, Gavin, \& Luckham, Robin, Governing insecurity. Democratic control of military and security establishments in transitional democracies, Estados Unidos, University of Chicago Press - Zed Books, 2003.

${ }^{28}$ HathazY, PAUL, "La (re)militarización policial en la Argentina post-crisis: entre intereses organizacionales e instrumentalización política en los campos policiales", Dilemas: Revista de Estudos de Conflito e Controle Social, vol. 9, núm. 1, pp. 181-213. 
La Ley 25.520 referida creó un control específico sobre las actividades de inteligencia; pero sus actividades no eran reportadas en los medios; tampoco eran objeto de visibilidad ciudadana.

Las conclusiones a las que llegan los expertos en seguridad en el Seminario sobre Seguridad y Democracia, realizado en el Congreso de la Nación en el mes de diciembre del 2012, refuerzan conclusiones ya formuladas con anterioridad: el control democrático de las fuerzas de seguridad es una tarea pendiente.

A principios del año 2013, la ADC, el Centro de Estudios Legales y Sociales (cels), el Instituto Latinoamericano de Seguridad y Democracia (Ilsed), la Fundación Vía Libre, y el Núcleo de Estudios de Gobierno y Seguridad (NEGYS-UMET) formulan la Iniciativa Ciudadana para el Control del Sistema de Inteligencia (ICCSI), cuyo objetivo es crear un espacio que vigile la democratización de los organismos de inteligencia con controles internos y externos que permitan el pleno ejercicio del Estado de derecho y de las instituciones democráticas. ${ }^{29} \mathrm{La}$ narrativa de la falta de control democrático de las fuerzas de seguridad conduce a la siguiente interrogante: ¿Por qué fracasan las iniciativas de control del sistema de inteligencia nacional? La respuesta es multidimensional, pero cada una de las partes tiene un denominador común que las relaciona:

El Sistema de Inteligencia Nacional depende del ejecutivo en la Ley 25.520 como en la Ley 27.126 producto de la reforma constitucional del 2015.

El sistema de inteligencia encarna dos principios contradictorios: 1) la rendición de cuentas, principio sustantivo democrático; y 2) la secrecía de la inteligencia que se ampara en argumentos de seguridad nacional y la consecuente ausencia de rendición de cuentas.

¿Cómo conciliar control civil de la inteligencia con la eficacia y efectividad de las instituciones de inteligencia?

La efectividad se asocia con la secrecía; y el fracaso con la visibilidad de las acciones.

Si la secrecía es efectividad, esta implica desconocimiento de la actividad de inteligencia de parte de actores políticos que deberían estar informados. La Comisión Bicameral, para ser más preciso.

El desconocimiento es un factor de vulnerabilidad, de inseguridad. De modo que la institución de seguridad se convierte en un factor de

\footnotetext{
${ }^{29}$ Iniciativa Ciudadana para el Control del Sistema de Inteligencia, 2013. [Consulta: 8 de julio, 2017]. Disponible en: http://www.iccsi.com.ar
} 
inseguridad y de violación de las libertades y las garantías constitucionales, como en los casos de vigilancia encubierta.

¿Son las instituciones de seguridad enclaves autoritarios o reminiscencias del autoritarismo? En diversos apartados se ha sostenido que el Estado argentino, si bien se afirma que su transición democrática ha sido exitosa, lo es en la medida en que se cumplen los requerimientos mínimos de una democracia poliárquica, pero exhibe enclaves autoritarios visibles en el presidencialismo, improntas autoritarias que se han calificado de formas delegativas, como el uso constante de los decretos presidenciales y de legislar al margen del poder legislativo. Los casos de Menem y Kirchner son ejemplos paradigmáticos del autoritarismo con su constante uso de los decretos.

Los servicios de inteligencia son enclaves del autoritarismo porque son una extensión del autoritarismo presidencial, de una democracia delegada. ${ }^{30}$

Emerge otra interrogante: ¿se democratiza la inteligencia nacional argentina en la AFI? Véase algunos artículos de la Ley $27.126^{31}$ que sustituye a la Secretaría de Inteligencia Nacional del Estado por la Agencia Federal de Inteligencia. Tomando en consideración que la inteligencia debe prever las tendencias del crimen, debe ser un instrumento de análisis para la seguridad nacional, la seguridad ciudadana y la seguridad pública. ${ }^{32}$

La Ley 27.126, título I, capítulo 1, artículo 2, define la inteligencia nacional como la "actividad consistente en la obtención, reunión, sistematización y análisis de la información específica referida a los hechos, riesgos y conflictos que afecten la Defensa Nacional y la seguridad interior de la Nación”; el artículo 3 señala: "Realizar tareas represivas, poseer facultades compulsivas, cumplir, por sí, funciones policiales". El artículo 5 bis determina que "la obediencia debida no podrá ser alegada como eximente de responsabilidad".

Sobre los fondos de los organismos de inteligencia los capítulos 6 y 18 contienen lo relativo a la transparencia en el uso de los recursos de la AfI: "se

\footnotetext{
30 O'Donnel, Guillermo, Disonancias: Críticas democráticas a la democracia, Buenos Aires, Prometeo Libros, 2007.

${ }^{31}$ La Ley de Inteligencia Nacional, 25.520, se integraba por diez títulos (incluyendo las disposiciones transitorias y complementarias) y 53 artículos. La Ley 27.126 se conforma por 3 títulos (incluyendo las Disposiciones transitorias) y por 30 artículos con la advertencia de que todos aquellos artículos de la Ley 25.520 que no hubieren sufrido modificación se considerarán hechos por la AfI. Para todo lo relacionado con esta normatividad, véase: Ley 27.126, Agencia Federal de Inteligencia, Ministerio de Justicia y Derechos Humanos, Presidencia de la Nación, Argentina, 3 de marzo, 2015. [Consulta: 26 de diciembre, 2016]. Disponible en: http://servicios.infoleg.gob.ar/infoleglnternet/ anexos/240000-244999/243821/norma.htm

${ }^{32}$ WALSH, PATRICK, Intelligence and Intelligence Analysis, New York, Routledge, 2011.
} 
establecerán mecanismos de contralor adecuados para el control de los montos asignados [...] compatibles a su clasificación de secreto, confidencial y público". En tanto, el artículo 19 indica que "Sólo podrán mantener carácter reservado los fondos que sean necesarios para labores de inteligencia, siempre y cuando no afecte la seguridad de las actividades propias de la función de inteligencia y quienes participen de las mismas”. Éstos, además de que se hacen públicos, establecen la figura del contralor y el control parlamentario a través de la Comisión Bicameral del congreso.

El artículo 32 establece que la fiscalización de los fondos está a cargo de la Comisión Bicameral. El artículo 25 establece criterios de transparencia en el ingreso del personal de inteligencia y la adopción de criterios de disciplina en los casos en que durante sus acciones hayan incurrido en violaciones a los derechos humanos. Se aprecia la importancia de los artículos 18, 19 y 32, que instauran mecanismos de rendición de cuentas horizontal y vertical: control interno y control externo, rendición de cuentas del sistema de inteligencia ante el Poder legislativo. Por último, el capítulo 7 reglamenta sobre el tipo de penas cuando un oficial o funcionario incurre en violaciones a la ley tales como la intercepción de las comunicaciones de las personas o realice acciones de inteligencia prohibidas por la ley.

No obstante, las voces críticas sobre la AFI se orientan hacia la democratización del sistema de seguridad y la rendición de cuentas. Éstas destacan que la Ley 27.126 no modifica de raíz el sistema, más bien apunta a darle más poder a la inteligencia militar, cuyo presupuesto aumentó significativamente entre 2007 y 2015 (700\%). La clara preponderancia de la agencia militar significa riesgos para la democracia..$^{33}$ Otras críticas subrayan que la Side sólo cambió de nombre puesto que únicamente traspasó la planta de empleados, inmuebles, presupuesto y su Sistema de Observaciones Judiciales a la nueva oficina. ${ }^{34}$

Por otra parte, el actual presidente Mauricio Macri (2015-2019), mediante el Decreto 656/2016, ${ }^{35}$ eliminó la obligación de registrar los recursos de la AFI (derogó el Régimen de Administración de la AFI) con el objetivo de agilizar las

\footnotetext{
${ }^{33}$ Tauber, NicolÁs, "De la afi a la Side solo cambio el nombre", Brújula Comunicación, 20 de julio, 2015. [Consulta: 4 de mayo, 2017]. Disponible en: http://brujulacomunicacion.com/index.php/noticias/notas/item/1377-de-la-afia-la-side-solo-cambio-el-nombre

${ }^{34}$ Maradeo, Julián y Damiani, Ignacio, El Tano, Buenos Aires, Ediciones B, 2016; véase también Tauber, Nicolás, "De la afl a la Side solo cambio el nombre", Brújula Comunicación, 20 de julio, 2015. [Consulta: 4 de mayo, 2017]. Disponible en: http://brujulacomunicacion.com/index.php/noticias/notas/item/1377-de-la-afi-a-la-side-solo-cambio-el-nombre ${ }_{35}$ Decreto 656/2016, Boletín Oficial, núm. 33374, Poder Ejecutivo Nacional, Agencia Federal de Inteligencia, 9 de mayo, 2016. [Consulta: 23 de junio, 2017]. Disponible en: http://servicios.infoleg.gob.ar/infolegInternet/verNorma. do? $i d=261157$
} 
instancias administrativas usuales de gestión. Con ello, incumplió el compromiso de "transparentar el sistema de utilización de fondos", volviendo a las prácticas discrecionales e irregulares de la agencia de inteligencia, señalaron CELs y la organización Memoria Abierta. ${ }^{36} \mathrm{Al}$ parecer, y por los acontecimientos analizados, nuevamente el secreto es la regla en el sistema de inteligencia del Estado argentino.

\subsection{Sistema de inteligencia de Chile}

La interrogante ahora en el caso chileno es la siguiente. ¿Cuál es el desempeño de del sistema de inteligencia y la rendición de cuentas de Carabineros y de la Policía de Investigaciones? El Sistema de Inteligencia se conduce por la Ley $19.974^{37}$ aprobada por el congreso el 2 de octubre del 2004 durante el gobierno de Ricardo Lagos Escobar (2000-2006). Según su artículo primero, la ley tiene por objeto "establecer y regular el Sistema de Inteligencia del Estado. Sus normas se aplicarán a toda la actividad de inteligencia que realicen los órganos y servicios que integren dicho sistema”.

En el encuadre anterior, el articulado de la Ley 19.974 define el concepto inteligencia de manera análoga a la argentina.

Artículo $2^{\circ}$.- Para los fines de esta ley y de las actividades reguladas por la misma, se entiende por: a) Inteligencia: el proceso sistemático de recolección, evaluación y análisis de información, cuya finalidad es producir conocimiento útil para la toma de decisiones. b) Contrainteligencia: aquella parte de la actividad de inteligencia cuya finalidad es detectar, localizar y neutralizar las acciones de inteligencia desarrolladas por otros Estados o por personas, organizaciones o grupos extranjeros, o por agentes locales, dirigidas contra la seguridad del Estado y la Defensa nacional.

176 Por su parte, el artículo 4 define el Sistema de Inteligencia del Estado. El entramado de inteligencia es el siguiente: Agencia Nacional de Inteligencia, Dirección de Inteligencia de Defensa del Estado Mayor de la Defensa Nacional,

\footnotetext{
36 PÁgina 12, "Todo lo contrario a la transparencia", 21 de mayo, 2016. [Consulta: 24 de mayo, 2017]. Disponible en: https://www.pagina12.com.ar/diario/elpais/1-299887-2016-05-21.html

${ }^{37}$ Ley 19.974, Sobre el Sistema de Inteligencia del Estado y crea la Agencia Nacional de Inteligencia, Ministerio del Interior, BCN, 2 de octubre, 2004. [Consulta: 14 de febrero, 2017]. Disponible en: $h$ ttp://www.leychile.cl/N?i=230999\&$f=2004-10-02 \& p$
} 
Direcciones de Inteligencia de las Fuerzas Armadas, y Direcciones o Jefaturas de Inteligencia de las Fuerzas del Orden y Seguridad Pública (artículo 5). En estas se encuentran Carabineros de Chile y Policía de Investigaciones (artículo 22). La actividad de estas comprende el procesamiento de información relacionada con actividades de grupos y organizaciones que afecten las condiciones del orden público y la seguridad pública interior. El artículo 23 establece que, si determinada información no puede obtenerse por fuentes abiertas, podrá conseguirse de fuentes cerradas mediante procedimientos especiales que serán limitados para resguardar la seguridad nacional y proteger a los chilenos de las amenazas del terrorismo, del crimen organizado y del narcotráfico.

Las fuerzas policiales del orden interno corresponden a Carabineros, de carácter militar, y la Policía de Investigaciones de Chile (PDI), de carácter civil, coadyuvante del Ministerio Público en asuntos de investigación criminalística. En los servicios de inteligencia policial, la ley establece que ésta corresponde de manera exclusiva a los Carabineros y a la PDI.

La Agencia Nacional de Inteligencia (ANI) es un organismo técnico, especializado. Su objetivo es producir inteligencia que requiera el ejecutivo y los ministerios de seguridad. Sus funciones están contempladas en el artículo 8.

Es importante realizar algunos señalamientos sobre los procedimientos legales que deben seguirse en la obtención de la información. El título v de la Ley 19.974, el artículo 23, dispone que si la información no puede obtenerse de fuentes abiertas, se recurra a procedimientos especiales en la obtención de la información con la autorización del organismo correspondiente. Estos procedimientos son: intervención telefónica, de redes informáticas, escucha de grabaciones y de sistemas de almacenamiento (artículo 24).

Los artículos 25 y 26 asientan que será mediante autorización judicial (ministro de la Corte de Apelaciones) que se aplicarán los procedimientos especiales a solitud de las direcciones de inteligencia. El plazo otorgado no será superior a los noventa días; podrá ser prorrogado por una sola vez. Estos artículos se complementan con el artículo 31 que permite a los funcionarios que recurran a los procedimientos especiales para ocultar su identidad.

Si bien, el manejo de los sistemas de inteligencia y contrainteligencia están debidamente estipulados, los organismos de inteligencia están sujetos a control interno y externo, según lo indica el artículo 33 de la ley. El primero (control interno) corresponde a la idónea utilización de los recursos humanos y técnicos; el empleo idóneo de los recursos asignados; la adecuación consistente de los procedimientos con el respeto de las garantías constitucionales. El segundo (control externo) le corresponde a la Contraloría General de la República, a los 
Tribunales de Justicia y a la Cámara de Diputados. ${ }^{38}$ Sobre esta última, la Comisión Especial de la Cámara conocerá los informes relativos a las actividades de los organismos de inteligencia. El director de la ANI informará anualmente a la Comisión sobre el trabajo realizado, pero también sobre el funcionamiento del sistema de inteligencia teniendo el carácter de información secreta.

Por último, y de acuerdo con los alcances de este trabajo, existe en la Ley 19.974 estipulaciones concretas de la obligación de guardar secreto. El artículo 38 precisa que en esta clasificación se encuentran los antecedentes, los informes y registros que dispongan los organismos del sistema de inteligencia. Por su parte, el artículo 43 estipula que los estudios y los informes que elaboren los organismos de inteligencia podrán eximirse de su carácter secreto sólo si lo dispone el director o jefe. Estipula, además, que cualquier funcionario que viole el carácter secreto de la información o que la utilice en beneficio propio o de otra persona será objeto de sanción con la pena de reclusión en sus grados mínimo a mayor y a la inhabilitación absoluta y perpetua para ejercer cargos.

El ejercicio de Carabineros en su función policial tiene dos facetas. Por una parte, se concibe como una institución eficaz en su tarea de detención de delincuentes. En 2006 hay 141, 893 órdenes recibidas y 78056 concluyen en detención. Es decir, hay 55.10\% de eficacia. En 2014 reciben 147523 órdenes de detención y 95400 son detenidos: la eficacia es de 64.66\%. Pero, por otra parte, es una institución que se ha visto degradada por actos de corrupción que alcanza a los altos niveles policiales: dos coroneles y un general. ${ }^{39}$ La investigación, que inicia en 2006, es una malversación de fondos de alrededor de 30 millones de dólares y envuelve a 70 personas: oficiales y civiles. El desfalco en Carabineros, institución prestigiada por su inserción en el ámbito comunitario, disminuye sus niveles de aprobación ciudadana en 17\%, para llegar a 37\% de aprobación ciudadana, por debajo de la Policía de Investigaciones, que en el periodo 2010-2014 es de 65\%.

¿Qué significan estas acciones de desfalco de los recursos de la institución policial? Que no hay monitoreo del uso de los recursos y rendición de cuentas interno, como tampoco ha habido efectividad en la rendición de cuentas externa 178 de parte de la Contraloría de Chile ni de la Comisión Especial Parlamentaria. El artículo 34 inciso b ha sido inaplicable; el director de la institución policial ha incumplido con su responsabilidad de control interno, de falta de supervisión y de cursar información engañosa a la Comisión Especial Parlamentaria en sus informes anuales. En materia del uso de los recursos de la institución policial, no se

\footnotetext{
${ }^{38}$ En el caso argentino es la Comisión Bicameral del Congreso.

39 "Carabineros de Chile enfrentan el mayor caso de corrupción de su historia", El Comercio. Disponible en: http:// www.elcomercio.com/actualidad/carabineros-chile-corrupcion-malversacion-michellebachelet.html
} 
aplica la rendición de cuentas de manera transparente, a pesar de la normatividad vigente. Véase la interpretación de la rendición de cuentas de la Contraloría chilena:

La rendición de cuentas es un proceso mediante el cual funcionarios, servidores públicos y particulares que manejan recursos del erario informan y explican, de manera detallada, ante la autoridad competente y ante la ciudadanía, las decisiones adoptadas en ejercicio de sus funciones, y responden por la gestión y resultados de sus acciones, siendo sujetos de las sanciones sociales y legales que el ordenamiento jurídico prevea, según si su manejo ha sido o no el adecuado a los propósitos definido. ${ }^{40}$

La rendición de cuentas comprende tres dimensiones: informativa, el receptor de fondos debe demostrar el resultado de su gestión; rendición de cuentas explicativa, esto es, justificar las acciones y decisiones tomadas; responsabilidad y acción, si las dos anteriores muestran infracciones al marco normativo, se abre la posibilidad de aplicar sanciones o tramitarlas ante la autoridad competente. Es evidente que, en el desfalco ocurrido en Carabineros, ninguna de las tres dimensiones de rendición de cuentas fue cumplida; pero también es un indicador de la disminución de la legitimidad del sistema político chileno y del régimen de gobierno en turno. La confianza en el gobierno es de 32\% en 2014, pero en 2016 desciende a 10\%; la confianza en el poder legislativo es 12\% en el 2014, pero descendió a 10\% en 2016 . $^{41}$

Véase el ejemplo siguiente de la falta de rendición de cuentas de Carabineros. La Contraloría de General de la República de Chile emite el dictamen, oficio número 67.704 del 2009, que dice a la letra: "se determinaron algunas debilidades relacionadas, principalmente, con el funcionamiento de la Unidad de Auditoría Interna de Dipreca”. Por su parte, la dirección interna de auditoria informa a Contraloría General de la República que las observaciones de fiscalización interna se encuentran pendientes de aplicación desde el año 2006, a pesar de las recomendaciones anuales que se emiten internamente. La Contraloría agrega, además, que la auditoria interna evidencia un engaño en su responsabilidad de control. ${ }^{42}$ Más aún, advierte que no hay concordancia de las cuentas bancarias en Dipreca, y no están al día. Ante estos hechos, Con-

\footnotetext{
40 "Rendición de cuentas", Contraloría, Chile. Disponible en: https://www.contraloria.cl/web/cgr/rendicion-de-cuentas3 ${ }^{41}$ Arana, Ignacio, "Chile. 2016. ¿El nadir de la legitimidad democrática?", Revista de Ciencia Política, vol. 37, núm. 2.

${ }^{42}$ Arriagada, Patricia, Informe final, No. 256, Contraloria General de la Republica, 2009.
} 
traloría recomienda una investigación para determinar las responsabilidades administrativas correspondientes.

La rendición de cuentas en la Policía de Investigaciones (PDI) comprende seis ${ }^{43}$ dimensiones. ${ }^{44}$ Para el caso que concierne a este trabajo, se examina sólo la rendición cuentas periódica que lleva a cabo la PDI desde el año 2004 en el gobierno del presidente Ricardo Lagos. En el marco de la nueva conceptualización de la seguridad, ésta se realiza internamente con los oficiales superiores y externamente con la ciudadanía mediante la entrega de información en ambos niveles de rendición de cuentas: rendición de cuentas de metas; rendición de cuentas de objetivos cumplidos; rendición de cuentas de participación ciudadana, consejos comunales y organizaciones; y de logros en operativos.

Respecto a la probidad policial y el control interno y externo, la PDI aplica dos estrategias: la recepción de denuncias anónimas y el análisis de consumo de drogas. Como resultado de este programa, 35 oficiales fueron detectados en el periodo del 2001-2005, y conminados a retiro voluntario. De las denuncias recibidas entre 2005 y 2006, 48.3\% se vincula con faltas de probidad y de conductas indebidas; el oficial es retirado, además de ser sometido a la justicia. Estos mecanismos de control interno y externo de la PDI respaldan la confianza ciudadana en la Policía de Investigación que en 2010-2014 es de 65\%.

\section{Conclusiones generales}

¿Qué conclusiones pueden formularse sobre la nueva ley de inteligencia nacional argentina? Una de las innovaciones sustantivas de la ley 27.126 frente a la ley 25.520 es la relativa al artículo 18 de la ley del 2001. En la reforma constitucional del 2015 se prohíbe de manera tajante la intercepción de comunicaciones de las personas. El artículo 20 de ley 27.126 establece penas de tres a diez años de prisión y la inhabilitación de los oficiales que intercepten las comunicaciones telefónicas, de correo, telegráficas, postales, o de cualquier sistema de envío de imágenes, de voces, paquetes de datos o archivos, sin mediar salvedad 180 o excepción alguna, como ocurría con la ley 25.520, artículos 18 a 22.

Desde la perspectiva de los derechos humanos, se tiene ahora un Sistema de Inteligencia Nacional con perspectiva de derechos humanos. Falta observar

\footnotetext{
${ }^{43}$ El desarrollo policial como objeto de responsabilidad, 2) Establecimiento de metas auditables, 3) Rendición de cuentas periódica, 4) Transparencia y gestión de informaciones, 5) Probidad y control interno/externo, 6) Buenas prácticas policiales.

${ }^{44}$ Herrera, Arturo, Experiencia de accountability en la Policía de Investigaciones de Chile, 2004-2007, Chile, Policia de Investigaciones de Chile, 2007.
} 
en qué medida se cumple la nueva normatividad de la ley 27.126. Sin embargo, la AFI, amparada en la permanencia del secreto, puede violar el derecho a la privacidad, los derechos políticos y los derechos democráticos. Su función de inteligencia securitaria no justifica la violación de los derechos humanos.

En la reforma del 2015 se conserva la definición de "secrecía" de la información, aspecto cuestionado de la ley del 2001, que aún se mantiene en la ley 27.126. Las fuerzas policiales o militares pueden cometer crímenes de lesa humanidad, y no se puede tener acceso a la información para investigar y castigar a los culpables. Este es el sentido de la crítica del Informe de la ADC y de las resoluciones de la Corte Interamericana de Derechos Humanos. ${ }^{45}$ Falta averiguar si la Comisión Bicameral del Congreso muestra el poder de ejercer el control democrático contenido en el artículo 18 de la ley 27.126. Este es uno de los grandes retos de la representación nacional argentina. El Estado burocrático autoritario aún sigue vigente. Las instituciones de seguridad aún no se democratizan, la calidad institucional argentina es baja frente a su vecino, Chile. La dimensión voz y rendición de cuentas que se presenta enseguida muestra la diferencia de este valor democrático entre uno y otro país.

\footnotetext{
${ }^{45}$ Asociación por los Derechos Civiles, El (des)control democrático de los organismos de inteligencia en Argentina, Argentina, ADC, 2015, p. 3. [Consulta: 8 de julio, 2017]. Disponible en: http://www.adc.org.ar/wp-content/ uploads/2015/01/2015-01-23-Informe-Final-Inteligencia.pdf
} 
Tabla 3. Valores democráticos. Argentina y Chile

\begin{tabular}{|l|c|c|}
\hline Calidad Institucional (periodo 1996-2006.) & Argentina $^{1}$ & Chile \\
\hline 1. Estado de derecho & 40.00 & 88.06 \\
\hline 2. Calidad regulatoria & 38.87 & 91.37 \\
\hline 3. Control de la corrupción & 34.87 & 89.5 \\
\hline 4. Efectividad de gobierno & 54.87 & 87.0 \\
\hline 5. Estabilidad política y ausencia de violencia & 43.87 & 70.87 \\
\hline 6. Voz y rendición de cuentas & 57.75 & 77.87 \\
\hline
\end{tabular}

Fuente: ORLANSKI, DorA, “Gobernanza, instituciones y desarrollo: Argentina en el contexto regional (1996-2008)”, V Congreso Latinoamericano de Ciencia Política, ALAcIP, Buenos Aires, 28-30 de julio, 2010. Escala: 0, nula; 100 máxima.

Pero no es sólo una problemática de rendición de cuentas vertical y horizontal; es también una cuestión de la autonomía de la que gozan las instituciones policiales, según afirmaciones de la $\mathrm{ADC}^{46} \mathrm{y}$ del cELs. ${ }^{47}$

Respecto al caso de Chile, los mecanismos de control interno y externo de la PDI enmarcados en el artículo 33 de la ley 19.974, además de incorporar a la sociedad en la vigilancia y fiscalización de los oficiales de la Policía de Investigaciones, han incidido en la disminución de faltas de probidad, como se ha mostrado en párrafos previos.

El índice policial del World International Security and Police Index (WISPI) detecta cómo el sistema policial responde a la seguridad interna, es decir, a la efectividad policial. De acuerdo con las variables del WISPI, el índice securitario policial de Argentina y Chile (véase tabla 4) indica una posición alta de corrupción policial en Argentina, sitio 77 de 127 países, en contraste con el índice policía chileno que está posicionado en el número 43 a nivel mundial.

Del análisis del sistema de inteligencia en Argentina y Chile y de su normatividad en el control y fiscalización de sus recursos, los indicadores de los valores democráticos de la tabla 3 se confirman las siguientes apreciaciones:

- Con el decreto 656/16 del presidente Macri, se aprueba el nuevo estatuto del personal de Agencia Federal de Inteligencia, que deroga la normativa reglamentaria de la ley de Inteligencia. La discrecionalidad

\footnotetext{
${ }^{46}$ Asociación por los Derechos Civiles, El (des)control democrático de los organismos de inteligencia en Argentina, Argentina, ADC, 2015. [Consulta: 8 de julio, 2017]. Disponible en: http://www.adc.org.ar/wp-content/ uploads/2015/01/2015-01-23-Informe-Final-Inteligencia.pdf

${ }^{47}$ Centro de Estudios Sociales y Legales, Derechos Humanos en Argentina. Informe Anual 2015, Buenos Aires, Siglo XXI, 2015.
} 
del Sistema de Inteligencia en sus acciones y del uso de los recursos se vuelven más oscuros y su función sujeta al poder político nacional.

- El artículo 32 de la ley 27.126 pierde vigencia con la derogación de la normatividad reglamentaria. Un ejemplo, adicional es la derogación del régimen de administración de fondos. Esta derogación ubica una vez a la AfI en el periodo de la Side.

- La labor de control y de fiscalización de la Comisión bicameral de fiscalización de las actividades de inteligencia se vulnera. Convierte al órgano de pesos y contrapesos en un fantasma legislativo en materia de inteligencia. En consecuencia, si no hay control de las actividades, tampoco lo hay en el uso de los recursos.

- Las improntas autoritarias, como los decretos, manifiestas a nivel nacional y a nivel provincial vulneran la rendición de cuentas, como en el caso argentino.

- En cambio, las políticas policiales securitarias democráticas en las que existen políticas de control interno y externo, rendición de cuentas horizontal y vertical, y la participación ciudadana-comunitaria, el índice policial securitario es robusto, como en el caso de Chile. El índice securitario policial de Chile es de 0.699, en tanto que el de Argentina es de 0.542; la posición de Chile a nivel mundial es de 43 de 127, mientras que la de Argentina es de 77 de $127 .{ }^{48}$

- La posición de Argentina y de Chile en el ranking mundial muestra el nivel de rendición de cuentas de Chile frente a Argentina en la escala de 0 (nula) y 100 (máxima).

- En el caso de Chile, la rendición de cuentas interna y externa le permite a la Policía de Investigación obtener una evaluación ciudadana de 65\% en 2014, mientras que Carabineros una evaluación de 20\% en el mismo año.

\section{REFERENCIAS}

Amnistía Internacional, "Chile: Un avance. Otro caso de violación de derechos humanos se traspasa a justicia ordinaria", Amnistía internacional. [Consulta: 8 de mayo, 2017]. Disponible en: https://www.amnesty.org/es/documents/ amr22/1149/2015/es/

\footnotetext{
${ }^{48}$ World Internal Security and Police Index, "International Police Science Association \& Institute for Economics and Peace", 2016. [Consulta: 30 de abril, 2017]. Disponible en: http://wispindex.org
} 
Arana, Ignacio, “Chile. 2016. ¿El nadir de la legitimidad democrática?”, Revista de Ciencia Política, vol. 37, núm. 2.

Archivo Chile, "Dictadura militar. Organismos represivos: DINA, CNI, SIFA, SIM, Sicar, Comando Conjunto”, Centro de Estudios Miguel Enríquez. [Consulta: 6 de julio, 2017]. Disponible en: http://www.archivochile.com/

Arriagada, Patricia, Informe final, No. 256, Contraloría General de la Republica, 2009.

Asociación por los Derechos Civiles, El (des)control democrático de los organismos de inteligencia en Argentina, Argentina, ADC, 2015. [Consulta: 8 de julio, 2017]. Disponible en: http://www.adc.org.ar/wp-content/ uploads/2015/01/2015-01-23-Informe-Final-Inteligencia.pdf

CAPARINI, María, "Controlling and Overseeing Intelligence Services in Democratic States”, Born Hans y Maria Caparini (eds.), Democratic control of Intelligence Services: containing Rogue Elephants, England \& USA, Ashgate Publishing, 2007.

"Carabineros de Chile enfrentan el mayor caso de corrupción de su historia”, El Comercio. Disponible en: http://www.elcomercio.com/actualidad/carabineros-chile-corrupcion-malversacion-michellebachelet.html

Carabineros de Chile, "Informe de Resultados de Gestión Operativa y Metas de Indicadores Institucionales”, Inspectoría General, Dcs. [Consulta: 30 de mayo, 2017]. Disponible en: http://www.senado.cl/site/presupuesto/2014/cumplimiento/Glosas\%202014/cuarta_subcomision/05\%20Interior\%202014/0RD. $\mathrm{N}^{\circ} \% 20249 / \mathrm{GLOSA} \% 20 \mathrm{~N}^{\circ} \% 203 . \mathrm{pdf}$

CARABineros de Chile, "Informe de Resultados de Gestión Operativa y Metas de Indicadores Institucionales", Inspectoría General, DCs. [Consulta: 11 de junio, 2017]. Disponible en: http://www.carabineros.cl/images/banner/111_GLOSA_N_3_2017.pdf

Cawthra, Gavin, \& LuckHam, Robin, Governing insecurity. Democratic control of military and security establishments in transitional democracies, Estados Unidos, University of Chicago Press - Zed Books, 2003.

Centro de Estudios Sociales y Legales, Derechos Humanos en Argentina. Informe Anual 2015, Buenos Aires, Siglo XXI, 2015.

Chacón, Rodrigo, “pdi habría solicitado la baja del prefecto Sandro Gaete”, Corporación Parque por la Paz Villa Grimaldi, DIBAm, Chile, 17 de diciembre de 2013. [Consulta: 29 de mayo, 2017]. Disponible en: HTTP://VILLAGRIMALDI.CL/ NOTICIAS/PDI-HABRIA-SOLICITADO-LA-BAJA-DEL-PREFECTO-SANDRO-GAETE/

Chillier, Gastón, "Prólogo”, Centro de Estudios Legales y Sociales, Derechos humanos en Argentina. Informe 2015, Buenos Aires, Siglo XXI - cels, 2015.

DAmiÁn GarCía, LEONARDo, “¿Cómo utilizaron los DNu los últimos presidentes?” [Consulta: 29 de mayo, 2017]. Disponible en: http://www.politicargentina.com/ notas/201512/10800-como-utilizaron-los-dnu-los-ultimos-ejecutivos.html 
Decreto 656/2016, Boletín Oficial, núm. 33374, Poder Ejecutivo Nacional, Agencia Federal de Inteligencia, 9 de mayo de 2016. [Consulta: 23 de junio, 2017]. Disponible en: http://servicios.infoleg.gob.ar/infolegInternet/verNorma. do?id=261157

Decreto 812/2005, Boletín Oficial, núm. 30694, Ministerio de Justicia y Derechos Humanos, República Argentina, 12 de julio de 2005. [Consulta: 23 de junio, 2017]. Disponible en: http://servicios.infoleg.gob.ar/infolegInternet/anexos/105000-109999/107751/norma.htm

Decreto ley 20.460, Ley Orgánica Policía de Investigaciones de Chile. Ministerio de Defensa Nacional. 9 de enero, 1979.

ECO, UMBERTo, Lector in fabula, Barcelona, Lumen, 1987.

ENUSc, Encuesta Nacional Urbana de Seguridad Ciudadana, Ministerio del Interior y Seguridad Pública, septiembre-diciembre 2014. [Consulta: 8 de julio, 2017]. Disponible en: http://www.seguridadpublica.gov.cl/media/2015/04/Presentacion-Resultados-ENUSC-2014.pdf

Gimate-Welsh HernÁndez, Adrián Sergio, Hacia un modelo de seguridad ciudadana y pública. Chile, Argentina y Uruguay, Madrid, Editorial Biblioteca Nueva, 2017.

Hathazy, Paul, "La (re)militarización policial en la Argentina post-crisis: entre intereses organizacionales e instrumentalización política en los campos policiales”, Dilemas: Revista de Estudos de Conflito e Controle Social, vol. 9, núm. 1.

Herrera, Arturo, Experiencia de accountability en la Policía de Investigaciones de Chile, 2004-2007, Chile, Policía de Investigaciones de Chile, 2007.

ICCSI, Iniciativa Ciudadana para el Control del Sistema de Inteligencia, 2013. [Consulta: 8 de julio, 2017]. Disponible en: http://www.iccsi.com.ar

IsEnBERG, DAVID, “The Pitfalls of U.S. Covert Operations”, Cato Institute Policy Analysis, núm. 118.

Jijón Calderón, Francisco, "El nuevo Ecuador y la Secretaría Nacional de Inteligencia”, Fredy Rivera Vélez (coord.), Inteligencia estratégica y prospectiva, Ecuador, Flacso - AECID - OCED, 2011.

Johnson, Lock, National Security Intelligence, Estados Unidos, Polity Press, 2012.

KABAT, CARINA, "El peronismo, los orígenes de la Side, y de la maldita policía”, Razón y Revolución, segunda época, núm. 29. Disponible en: revistaryr.org.ar/index.php/RyR/article/viewFile/556/577

LA NACión, “Atentado a la AMIA”, La Nación. [Consulta: 22 de febrero, 2017]. Disponible en: http://www.lanacion.com.ar/atentado-a-la-amia-t48671

LA NAción, "Pasado, presente y futro de la Side", La Nación. [Consulta: 11 de abril, 2017]. Disponible en: http://www.lanacion.com.ar/841630-pasado-presente-y-futuro-de-la-side

Ley 19.974, "Sobre el Sistema de Inteligencia del Estado y crea la Agencia Nacional de Inteligencia”, Ministerio del Interior, всN, 2 de octubre de 2004. [Consulta: 
14 de febrero, 2017]. Disponible en: http://www.leychile.cl/N?i=230999\&$\mathrm{f}=2004-10-02 \mathrm{Ctp}$

Ley 20.798, “Ley de Presupuestos del Sector Público Año 2015”, Diario Oficial, 6 de diciembre, 2014, Ministerio del Interior y Seguridad Pública. [Consulta: 27 de junio, 2017]. Disponible en: http://www.dipres.gob.cl/594/articles-121592_Ley_de_Presupuestos_2015.pdf

Ley 25.520, "Ley de Inteligencia Nacional”, Ministerio de Justicia y Derechos Humanos, Presidencia de la Nación, Argentina. [Consulta: 20 de diciembre, 2016]. Disponible en: http://servicios.infoleg.gob.ar/infolegInternet/anexos/70000-74999/70496/texact.htm

Ley 27.126, “Agencia Federal de Inteligencia”, Ministerio de Justicia y Derechos Humanos, Presidencia de la Nación, Argentina. [Consulta: 26 de diciembre, 2016]. Disponible en: http://servicios.infoleg.gob.ar/infolegInternet/anexos/240000-244999/243821/norma.htm

Mainwaring, Scott \& Christoper Welna, Democratic Accountability in Latin America, Oxford, Oxford University Press, 2003.

Maradeo, Julián y Damiani, Ignacio, El Tano, Buenos Aires, Ediciones B, 2016.

O’Donnell, Guillermo, El Estado burocrático autoritario, Buenos Aires, Belgrano, 1982.

O’Donnell, Gullerermo, “Estado, democratización y ciudadanía”, Revista Nueva Sociedad, núm. 128.

O’Donnell, Guillermo, "Horizontal Accountability and New Polyarchies”, Working Paper 253, Helen Kellogg Institute of International Studies, Notre Dame University, 1998.

O’Donnell, Gulleremo, "Horizontal Accountability in New Democracies”, A. Schedler, L. Diamond and M. F. Plattner (eds.), The Self-Restraining State: Power and Accountability in New Democracies, Boulder, Lynne Rienner Publishers, 1999.

O’Donnell, Guillermo, “Accountability horizontal. La institucionalización legal de la desconfianza política”, Isonomía, núm. 14.

O’Donnell, Gulleremo, “Acerca de varias accountabilities y sus interrelaciones”, Catalina Smulovitz y Enrique Peruzzotti (eds.), Controlando la politica: Ciudadanos, medios en las nuevas democracias Latinoamericanas, Buenos Aires, Editorial Temas, 2002.

O’Donnell, Guillermo, Disonancias: Críticas democráticas a la democracia, Buenos Aires, Prometeo Libros, 2007.

UnoDoc, Oficina de las Naciones Unidas Contra la Droga y el Delito, Policía. Integridad y responsabilidad de la policía, Viena, Nueva York, unodc, 2010.

unodoc, Oficina de las Naciones Unidas Contra la Droga y el Delito, Policía. Sistemas de información e inteligencia, Viena, Nueva York, unODC, 2010.

OrLANSKI, Dora, “Gobernanza, instituciones y desarrollo: Argentina en el contexto 
regional (1996-2008)", V Congreso Latinoamericano de Ciencia Política, Buenos Aires, ALACIP, 28-30 de julio, 2010.

PÁgina 12, "Todo lo contrario a la transparencia”, Página 12, 21 de mayo, 2016. [Consulta: 24 de mayo, 2017]. Disponible en: https://www.pagina12.com. ar/diario/elpais/1-299887-2016-05-21.html

Pereira da Rocha, Alexandre, “A gramática das policías militarizadas. Estudo comparado entre a policía militar do Estado do Sao Paulo e Carabineros de Chile em regímenes políticos autoritarios e democráticos”, XXIX Congreso Latinoamericano de Sociología, ALAS, Chile, 2013.

Policía de Investigaciones de Chile, Informe de Resultados. Gestión Operativa. Año 2014, marzo 2015. [Consulta: 9 de julio, 2017]. Disponible en: https:// www.pdichile.cl/paginas/accountability/2015/30marzo015/Informe\%20resultados\%202014.pdf

Policía de Investigaciones De Chile, "Informe de Resultados. Gestión Operativa”, Ministerio del Interior y Seguridad Pública, 2007-2015. [Consulta: 30 de enero, 2016]. Disponible en: http://www.pdichile.cl/

Policia de Investigaciones de Chile, "Plan Estratégico de Desarrollo Institucional - Minerva II, 2010-2015, Resumen Ejecutivo”, Policía de Investigaciones de Chile. [Consulta: 9 de julio, 2017]. Disponible en: http://www.pdichile.cl/ paginas/publicaciones/plan\%20minerva/2011_/Resumenej_MinervaII.pdf

Presidencia de la Nación Argentina, "Reforma del Sistema de Inteligencia del Estado", 27 de febrero de 2015. [Consulta: 13 de enero, 2016]. Disponible en: http:// www.casarosada.gob.ar/informacion/discursos/28321-reforma-del-sistema-de-inteligencia-del-estado-anuncio-de-la-presidenta-de-la-nacion-por-cadena-nacional

Real decreto 304/2014, Boletín Oficial del Estado, Reglamento de la Ley 10/2010 de Prevención de Blanqueo de Capitales y de la Financiación del Terrorismo, No. 110, 6 de mayo de 2014. [Consulta: 7 de julio, 2017]. Disponible en: https://www.boe.es/diario boe/txt.php?id=BOE-A-2014-4742

Reisman, Michael, "Covert Action”, Yale Journal of International Law, vol. 20.

"Rendición de cuentas”, Contraloría, Chile. Disponible en: https://www.contraloria. $\mathrm{cl} /$ web/cgr/rendicion-de-cuentas3

Salomón, Alejandro, "Pasado y presente de la Side. El repaso por lo que es hoy la Secretaría de Inteligencia”, 26 de enero, 2015. [Consulta: 11 de abril, 2017]. Disponible en: http://www.mdzol.com/opinion/584497-pasado-y-presente-de-la-side/

Serrano Torres, Jorge, “¿Acabará la manipulación e ineficacia? Kirchner y el sistema de inteligencia argentino", Voltaire Net, 26 de septiembre, 2004. [Consulta: 2 de enero, 2016]. Disponible en: http://www.voltairenet.org/article121590. html 
TAuber, Nicolás, "De la AFI a la Side solo cambio el nombre”, Brújula Comunicación, 20 de julio, 2015. [Consulta: 4 de mayo, 2017]. Disponible en: http://brujulacomunicacion.com/index.php/noticias/notas/item/1377-de-la-afi-a-laside-solo-cambio-el-nombre

Taylor, Stan \& Kayle Buchanan, “Treason: “Tis Worse than Murder”, Johnson, Loch K., The Oxford Handbook of National Security Intelligence, New York, Oxford University Press, 2010.

TÉLAM, "Amia: los fiscales alertan que la ex-Side no envió información a la justicia”, 16 de octubre, 2016. [Consulta: 2 de enero, 2016]. Disponible en: http:// www.telam.com.ar/notas/201610/167167-causa-amia-fiscales-ex-side-informacion.html

Ugarte, José Manuel, "La inteligencia criminal en la seguridad pública Argentina”, en Enrique Percio (coord.), Prejuicio, crimen y castigo, Buenos Aires, Sudamericana, 2010.

United Nations Office on Drug and Crime, Criminal Intelligence. Manual for Analysts, New York, unodc, 2011.

URGente 24, "Pacto de Irán: denuncia y pedido de indagatoria a Cristina”, [Consulta: 5 de mayo, 2017]. Disponible en: http://www.urgente24.com/235435-pacto-con-iran-denuncia-y-pedido-de-indagatoria-a-cristina

WaLSh, PATRICK, Intelligence and Intelligence Analysis, New York, Routledge, 2011.

World Internal Security and Police Index, "International Police Science Association Et Institute for Economics and Peace”, 2016. [Consulta: 30 de abril, 2017]. Disponible en: http://wispindex.org 